\title{
DEVELOPMENT OF HEALTH PROMOTION MEDIA TO CONTROL RABIES CASE IN BALI
}

\author{
Komang Hendra Setiawan',2), Didik Gunawan Tamtomo'), \\ Ari Natalia Probandari'), Eti Poncorini Pamungkasari1) \\ 1)Doctoral Program in Medicine, Universitas Sebelas Maret \\ 2)Faculty of Sport and Health, Ganesha University of Education, Singaraja
}

\begin{abstract}
Background: Rabies is one of the deadly Neglected Tropical Diseases (NTDs). Rabies spread in Bali since 2008. In 2016, a rabies-positive dog was found in 41 villages in Buleleng District. Until now there is no cure for rabies, therefore prevention efforts through health promotion are very necessary. The aim of this study was to develop family-based health promotion media to control rabies.

Subjects and Method: This was a qualitative development study conducted in Buleleng District, Bali from January to February 2018. A Sample of 20 families who had dogs in Buleleng was selected for the study. In addition, the key informants included representatives of the health service, the livestock and agriculture service, village apparatus, and religious leaders. The development of the promotion media proceeded in five steps: analysis, design, development, implementation, and evaluation. The analysis phase aimed to assess need of health promotion. The design and development stages aimed to make a blueprint of media for health promotion. It also tested the media by doctors. The implementation and evaluation stages aimed to test by the users for its benefits. The data were collected by in-depth interview and focus group discussion (FGD). Results: A family-based health promotion media has been developed. The promotional media is called "Rabies Eradication Package" which consisted of (1) Rabies Eradication Book, (2) Card History of anti-rabies vaccine (VAR) and (3) Rabies Eradication Box. Rabies Eradication Book was a book containing all the information about rabies prevention. The VAR History Card was used to record the VAR schedule. Rabies Eradication Box is a box that contains a dog bite wound treatment tool. The package was given for 1 month. Before the rabies eradication package, only 2 families (10\%) knew how to prevent rabies through post-exposure prophylaxis (PEP). At the end of the intervention, 20 families (100\%) knew the correct PEP action.

Conclusion: Rabies Eradication Package "consists of Rabies Eradication Book, VAR History Card (anti-rabies vaccine) and Rabies Eradication Box can increase family knowledge about PEP actions.
\end{abstract}

Keywords: rabies, intervention, health promotion media, family-based

\section{Correspondence:}

Komang Hendra Setiawan. Doctoral Program in Community Empowerment, Universitas Sebelas Maret. Email: komanghendra@gmail.com.

Mobile: 081703597792. 